\title{
La red nivometeorológica de AEMET en Aragón y Navarra
}

https://doi.org/10.31978/639-19-010-0.109

\author{
Samuel T. Buisán Sanz ${ }^{1}$ (sbuisans@magrama.es)
}

${ }^{1}$ AEMET / Delegación Territorial en Aragón

\section{RESUMEN}

La disponibilidad de datos de observación sistemáticos manuales con continuidad espacial y temporal a partir de cierta altitud a nivel nacional es escasa. Solamente en el Pirineo aragonés y navarro existe una mínima red de observación en altura que cumpla las premisas anteriores. Esta singularidad de gran valor meteorológico se puede explotar en numerosas aplicaciones como predicción, climatología y zona de ensayo de instrumentos de medida en entornos extremos.

Esta red se compone de 20 puntos de observación que de manera continuada los 365 días al año, excepto 4 estaciones de esquí que solo lo hacen en periodo invernal, emiten información de tipo sinóptico además de información nivológica en época invernal. Además, todos los puntos de observación por encima de $2000 \mathrm{~m}$ forman parte de la red internacional de Vigilancia de la Criosfera de la Organización Meteorológica Mundial y uno de ellos, Cap de Llauset, es la estación manual a mayor altitud de España (2425 m).

Este trabajo presenta la utilidad, las virtudes, las limitaciones y la complejidad asociadas tanto al mantenimiento como a la explotación de sus datos meteorológicos por parte de AEMET.

PALABRAS CLAVE: Pirineo; observación; nieve; OMM. 
